\title{
Rancang Bangun Aplikasi Enkripsi Citra Berdasarkan Operasi Rotasi
}

\author{
Bagus Prasetyo Wahyudianto* ${ }^{*}$, Diah Risqiwati ${ }^{2}$, Denar Regata $\mathbf{A k b i}^{3}$ \\ 1,2,3 Teknik Informatika/Universitas Muhammadiyah Malang \\ herozyko@gmail.com ${ }^{* 1}$,diah.rizqiwati@gmail.com², dnarregata@umm.ac.id ${ }^{3}$
}

\begin{abstract}
Abstrak
Kriptografi yakni disiplin ilmu yang menggunakan persamaan matematika ketika melakukan proses dekripsi sampai enkripsi. Teknik ini memakai untuk mengubah pesan awal menjadi bentuk kode-kode tertentu, pada penelitian ini menggunakan metode rotasi, metode rotasi sendiri adalah algoritma untuk memutar citra pada porosnya pada sebagian dari citra. Yang bertujuan supaya informasi yang disimpan dan dikirim ke penerima tidak dapat dibaca atau tidak mudah di pahami oleh pihak ketiga atau pihak-pihak yang tidak berhak, keungulan dari penelitian yang dibuat adalah kecepatan proses aplikasi yang cepat serta terjadinya penurunan size file dan tidak mudah dekripsi manual dengan tools lain, Hasil percobaan aplikasi enkripsi terjadinya pemampatan size file yang terjadi sesudah proses dekripsi maupun enkripsi jika dibanding dengan ukuran awal file citra, dan tidak terjadi penurunan size file pada ektensi BMP, kecepatan waktu enkripsi terhadap file dan ukuran pixel pada citra file berektensi BMP dan PNG pada ukuran pixel $2000^{\times} 2000$ memiliki peningkatan kecepatan terbaik yaitu sebesar 0.12x lebih cepat, serta perubahan histogram pada citra awal dengan hasil enkripsi. Penelitian ini di bangun dengan menggunakan bahasa pemprograman Python 3.4, dan ditambah dengan Library PIL-pillow, Library Time.
\end{abstract}

Kata kunci: Kriptografi, Rotasi, Python, Rotasi Citra, Kriptografi Citra

\section{Abstract}

Cryptography is a discipline that uses mathematical equations when doing the decryption process until encryption. This technique uses to convert the initial message into the form of certain codes, in this study using the rotation method, the rotation method itself is the algorithm to rotate the image on its axis in part of the image. Aiming that information stored and sent to the recipient can't be read or not easily understood by a third party or parties that are not eligible, advantages of the research made is the speed of fast application process and the decline in file size and not easy manual decryption With other tools, the result of encryption application encoding the occurrence of file size that occurs after the decryption process and encryption when compared with the initial size of the image file, and there is no decrease in the size of the file on BMP extension, the speed of encryption time to the file and the pixel size in the image file extension BMP And PNG on 2000x2000 pixel size has the best speed improvement that is equal to $0.12 x$ faster, and change the histogram in the initial image with the result of encryption. This research is built using Python 3.4 programming language, and coupled with Library PIL-pillow, Library Time.

Keywords: Cryptography, Rotate, Python, Rotate Images, Cryptography Image

\section{Pendahuluan}

Kriptografi dalam disiplin ilmunya berupa seni dan ilmu yang bertujuan menjaga kerahasiaan [1]. Pesan maupun data informasi. Pesan asli biasanya disebut juga dalam plain image. Sedangkan pesan yang sudah diamankan disebut chipper image [2]. Dalam jenisnya kriptografi dibagi menjadi 2 , yakni klasik dan modern [3]. Dimana dalam penerapannya, kriptografi modern biasanya digunakan sebagai teknik keamanan data, akan tetapi masih ada juga pengguna yang memakai teknik keamanan klasik dengan cara merangkap 2 algoritma klasik sehingga menghasilkan tingkat keamanan teknik klasik yang lebih tinggi.

Dalam persoalan citra terdapat algoritma operasi dipakai bertujuan untuk dapat menyembunyikan data atau pesan yang nantinya ditransmisikan. Operasi rotasi adalah membalikkan dengan mengambil y atau 2 ту [4]. operasi akan dikendalikan dengan memutar 
pusat, jari-jari dan sudut y. operasi akan dikendalikan dengan memutar pusat, jari-jari dan sudut y.

Python adalah bahasa pemrograman interpretatif multiguna dengan disisplin ilmu perencanaan yang berpusata pada tingkat bacaan kode [5]. Bahasa python diakui sebagai bahasa yang memadukan kemampuan, kapabilitas, dengan code pemprograman yang jelas, dan ditambahkan dengan fungsi-fungsi pustaka standar yang besar serta komprehensif [6].

Keunggulan penelitihan ini yaitu proses kecepatan enkripsi yang cepat jika perbandingan dengan tools manual yang lain serta terjadinya perubahan size file pada citra setelah file citra tersebut dienkripsi, dan kita dapat merubah file ektensi citra yang didekripsi maupun dienkripsi.

\section{Metode Penelitian}

Pada Gambar 1 dapat dilihat bahwa komponen sistem kriptografi yang dibangun terdiri dari proses dekripsi dan enkripsi. proses pada masing-masing bagian tetaplah sama. Setiap proses dekripsi dan enkripsi harus memasukan key yang sama agar dapat di buka.

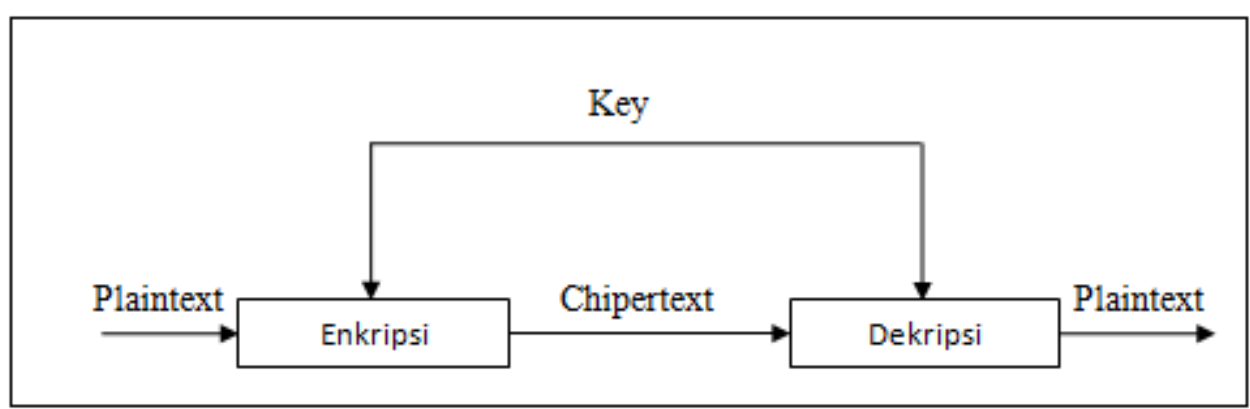

Gambar 1. Proses kriptografi Simetris [6]

\subsection{Operasi Rotasi}

Operasi rotasi merupakan teknik pengolahan image dengan merubah koordinat pixel namun tidak mengubah nilai intensitasnya yang disebut juga sebagai salah-satu jenis transformasi geometri[7]. Prinsip operasi rotasi yakni memindahkan nilai-nilai pixel dari posisi awal menuju posisi akhir yang ditentukan oleh nilai batasan pixe/ yang diputar terhadap $\operatorname{sudut}\left(\theta^{\circ}\right)$.

Cara kerja operasi rotasi yakni mentransformasikan ketetapan tiap titik pada bidang dengan memutar pada pusat titik tersebut. Titik pusat berada didalam citra dengan bentuk bangun persegi yang akan diputar. Teknik operasi rotasi menggunakan persamaan matematika berikut [4].

$$
\begin{gathered}
I_{o}^{\prime}=R\left(I_{o} ; x_{o}, y_{o}, r, \theta\right) \\
I_{o}^{\prime}=R\left(I_{o} ; x_{o}, y_{o}, r,-\theta\right)
\end{gathered}
$$

Dalam teknis persamaan matematika diatas dengan konsep poros $X$ dan $Y$. Sehingga mengalami perpotongan sehingga menghasilkan empat persegi. Untuk $r$ digunakan sebagai identitas area yang dirotasi. Dalam persamaan matematika operasi rotasi Persamaan 1 digunakan untuk tahap enkripsi dan Persamaan 2 digunakan untuk tahap dekripsi. Perbedaannya yakni pada derajat rotasi $(\theta)$ pada enkripsi menggunakan nilai positif sedangkan dekripsi menggunakan nilai negatif.

\subsection{Alur Sistem}

Alur sistem enkripsi Gambar 2 yakni dengan menginputan citra, dengan menginputkan nama file dan ektensi file dalam aplikasi enkripsi, dengan ukuran pixel minimal 40x40 dan maksimal 2000x2000. Dengan citra yang sudah diinputkan, citra akan dicek ukuran pixelnya. Ketika ukuran pixel tidak dapat dibagi oleh modulus 8, citra akan melalui proses normalisasi. Proses normalisasi adalah proses resize citra agar bisa diproses oleh algoritma rotasi agar dapat dimodulus 8 . Dengan ukuran yang sudah dinormalisasi, citra akan dirotasi dengan key yang akan diinputkan. Dimana pada proses ini pengimputan key menggunakan 7 digit angka, huruf, maupun simbol.

REPOSITOR, Vol. 1, No. 1, November 2019: 1-8 
Dengan inputan setiap digit pada key yang sudah ditetapkan perwakilan berapa derajat rotasi pada setiap pixe/nya. Beberapa pixe/yang berada dalam citra akan berotasi sesuai dengan ketetapan nilainya sesuai dengan inputan key, membuat citra akan teracak dengan berbagai variasi putaran. Tahap akhir dalam proses enkripsi yakni pemberian nama pada citra hasil enkripsi dengan menuliskan nama file dan ektensi file sehingga keluaran citra hasil enkripsi dapat dilihat hasilnya.

Alur sistem dekripsi Gambar 3 yakni dengan menginputan citra, dengan menginputkan nama file dan ektensi file dalam aplikasi dekripsi, Citra akan dirotasi sesuai key yang diinputkan. Dimana pada proses ini key mengguakan 7 digit angka, huruf, maupun simbol.

Dengan inputan setiap digit pada key yang sudah ditetapkan perwakilan berapa derajatnya. Beberapa pixel yang berada dalam citra akan berotasi sesuai dengan ketetapan nilainya sesuai dengan inputan key, membuat citra yang awalnya teracak menjadi citra awal. Setelah proses rotasi selesai, citra hasil dekripsi inilah yang disebut dengan plaintext.

Berbeda dengan proses enkripsi, proses deskripsi berkebalikan proses enkripsi. Artiannya, secara proses menginputan citra sama dengan proses enkripsi namun pada proses perotasian pixelnya berbeda.

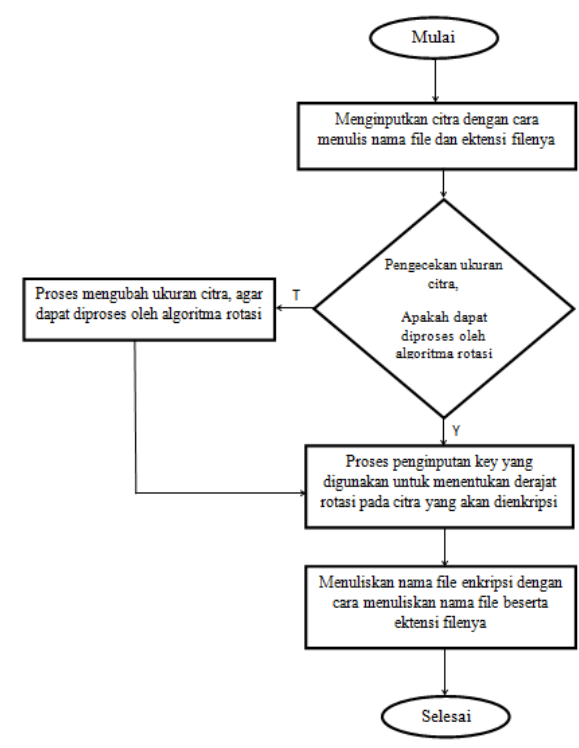

Gambar 2. Alur Sistem Enkripsi

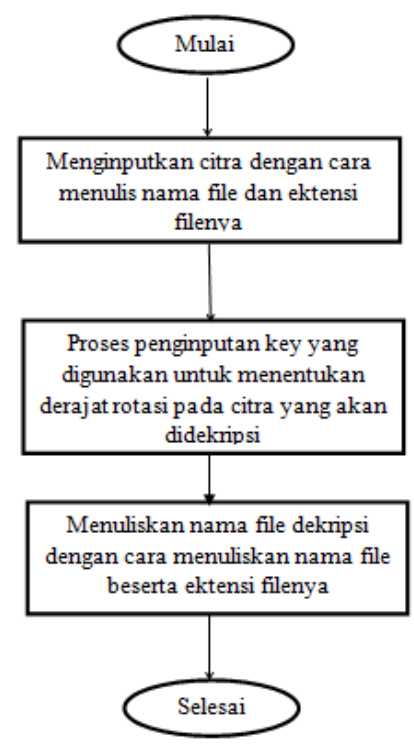

Gambar 3. Alur Sistem Dekripsi 
3. Hasil Penelitian dan Pembahasan

Pengujian Aplikasi Enkripsi dieksekusi dengan melakukan beberapa percobaan pada aplikasi. Data hasil uji pada aplikasi akan dianalisis sehingga menyimpulkan analisis dari aplikasi ini. Pengujian yang akan dilakukan pada aplikasi :

1. Perubahan size file saat proses enkripsi

2. Perubahan size file saat proses dekripsi

3. Kecepatan enkripsi

4. Analisis ruang kunci

5. Analisis histogram

\subsection{Perubahan Size File Saat Proses Enkripsi} dienkripsi.

Tujuan pengujian ini untuk mengetahui perubahan size file sebelum dienkripsi dan setelah

Skenario pada pengujian penelitihan akan dilakukan dengan beberapa percobaan ektensi file awal dan di rubah saat selesai proses enkripsi.

Tabel 1. Hasil Pengujian Size File

\begin{tabular}{ccccccc}
\hline No. & $\begin{array}{c}\text { Ektensi } \\
\text { awal }\end{array}$ & $\begin{array}{c}\text { Size file } \\
\text { (KB) }\end{array}$ & $\begin{array}{c}\text { Ektensi } \\
\text { Setelah } \\
\text { Proses }\end{array}$ & $\begin{array}{c}\text { Size file } \\
\text { (KB) }\end{array}$ & $\begin{array}{c}\text { Perubahan } \\
\text { Size file } \\
\text { (KB) }\end{array}$ & $\begin{array}{c}\text { Perbandingan } \\
\text { size file }\end{array}$ \\
\hline 1. & JPG & 275 & JPG & 74 & -201 & $-0,73091$ \\
2. & PNG & 515 & PNG & 527 & 13 & 0,025243 \\
3. & BMP & 1876 & BMP & 1876 & 0 & 0 \\
4. & GIF & 133 & GIF & 87 & -46 & $-0,34586$ \\
5. & TIFF & 1450 & TIFF & 2321 & 871 & 0,60069 \\
\hline
\end{tabular}

Hasil dari analisis Tabel 1 yang didapat dari pengujian perubahan size file sebelum dienkripsi dan setelah dienkripsi. Terjadi penurunan size file pada ektensi JPG dan GIF. Untuk ektensi PNG dan TIFF terjadi peningkatan size file dan tidak ada perubahan size file pada ektensi BMP.

\subsection{Perubahan Size File Saat Proses Dekripsi}

Tujuan pengujian penetilihan untuk mengetahui perubahan size file setelah dienkripsi dan setelah didekripsi.

Skenario pada pengujian ini akan dilakukan dengan beberapa percobaan ektensi file awal dan di rubah saat selesai proses enkripsi.

Pengujian ini menggunakan hasil dari ektensi awal TIF yang di ubah menjadi JPG, PNG, MBP, dan GIF.

Tabel 2. Hasil Pengujian Ukuran Data

\begin{tabular}{ccccccc}
\hline No. & $\begin{array}{c}\text { Ektensi } \\
\text { awal }\end{array}$ & $\begin{array}{c}\text { Size file } \\
(\mathrm{KB})\end{array}$ & $\begin{array}{c}\text { Ektensi } \\
\text { Setelah } \\
\text { Proses }\end{array}$ & $\begin{array}{c}\text { Size file } \\
(\mathrm{KB})\end{array}$ & $\begin{array}{c}\text { Perubahan } \\
\text { Size file } \\
(\mathrm{KB})\end{array}$ & $\begin{array}{c}\text { Perbandingan } \\
\text { size file }\end{array}$ \\
\hline 1. & JPG & 74 & JPG & 71 & -3 & $-0,040541$ \\
2. & PNG & 527 & PNG & 519 & -8 & $-0,015181$ \\
3. & BMP & 1876 & BMP & 1876 & 0 & 0 \\
4. & GIF & 86 & GIF & 84 & -2 & $-0,023256$ \\
5. & TIFF & 2321 & TIFF & 2299 & -22 & $-0,009479$ \\
\hline
\end{tabular}

Hasil dari analisis Tabel 2 yang didapat dari pengujian perubahan size file sebelum dienkripsi dan setelah dienkripsi, Terjadi penurunan size file pada ektensi JPG, PNG, GIF, dan TIFF. tetapi tidak ada penurunan size file pada ektensi BMP.

Kesimpulan dari percobaan perubahan size file adalah hanya file berektensi BMP mempunyai aspek layanan keamanan data yaitu keutuhan data (Data Integrity), dikarenakan hanya file berektensi BMP yang mempunyai size file yang sama dengan file asli, sedangkan untuk ektensi yang lainnya, mengalami penurunan size file sehingga berbeda dengan file awal. 
3.3 Kecepatan Proses Enkripsi

Tujuan pengujian ini untuk mengetahui kecepatan enkripsi citra, skenario pada pengujian penelitihan akan dilakukan dengan beberapa percobaan ektensi dan ukuran pixel yang berbeda.

Tabel 3. Hasil Pengujian Kecepatan Enkripsi

\begin{tabular}{ccccccc}
\hline No. & $\begin{array}{c}\text { Ektensi } \\
\text { File }\end{array}$ & $\begin{array}{c}\text { Ukuran } \\
\text { pixel }\end{array}$ & $\begin{array}{c}\text { Kecepatan } \\
\text { percobaan } \\
1(\mathrm{~s})\end{array}$ & $\begin{array}{c}\text { Kecepatan } \\
\text { percobaan } \\
2(\mathrm{~s})\end{array}$ & $\begin{array}{c}\text { Kecepatan } \\
\text { percobaan } \\
3(\mathrm{~s})\end{array}$ & $\begin{array}{c}\text { Perbandingan } \\
\text { waktu } \\
\text { percobaan } 3 \\
\text { dan } 1\end{array}$ \\
\hline 1. & BMP & $2000 \times 2000$ & 1,30208333 & 0,171875 & 0,15625 & 0,12 \\
2. & BMP & $1500 \times 1500$ & 0,109375 & 0,09375 & 0,109375 & 1 \\
3. & BMP & $1000 \times 1000$ & 0,03125 & 0,046875 & 0,046875 & 1,5 \\
4. & BMP & $500 \times 500$ & 0,015625 & 0,015625 & 0,015625 & 1 \\
5. & BMP & $250 \times 250$ & 0,015625 & 0,015625 & 0,015625 & 1 \\
6. & GIF & $2000 \times 2000$ & 0,078125 & 0,078125 & 0,078125 & 1 \\
7. & GIF & $1500 \times 1500$ & 0,03125 & 0,03125 & 0,046875 & 1,5 \\
8. & GIF & $1000 \times 1000$ & 0,015625 & 0,03125 & 0,015625 & 1 \\
9. & GIF & $500 \times 500$ & 0,015625 & 0,015625 & 0,015625 & 1 \\
10. & GIF & $250 \times 250$ & 0,015625 & 0,00965 & 0,00965 & 0,6176 \\
11. & JPG & $2000 \times 2000$ & 0,171875 & 0,171875 & 0,171875 & 1 \\
12. & JPG & $1500 \times 1500$ & 0,109375 & 0,109375 & 0,09375 & 0,857143 \\
13. & JPG & $1000 \times 1000$ & 0,03125 & 0,046875 & 0,046875 & 1,5 \\
14. & JPG & $500 \times 500$ & 0,015625 & 0,015625 & 0,015625 & 1 \\
15. & JPG & $250 \times 250$ & 0,00955 & 0,00955 & 0,00955 & 1 \\
16. & PNG & $2000 \times 2000$ & 1,30208333 & 1,302083 & 0,15625 & 0,12 \\
17. & PNG & $1500 \times 1500$ & 0,09375 & 0,09375 & 0,109375 & 1,166667 \\
18. & PNG & $1000 \times 1000$ & 0,046875 & 0,046875 & 0,015625 & 0,333333 \\
19. & PNG & $500 \times 500$ & 0,015625 & 0,015625 & 0,00978 & 0,62592 \\
20. & PNG & $250 \times 250$ & 0,00955 & 0,00955 & 0,00955 & 1 \\
21. & TIF & $2000 \times 2000$ & 1,30208333 & 1,302083 & 0,171875 & 0,132 \\
22. & TIF & $1500 \times 1500$ & 0,09375 & 0,109375 & 0,109375 & 1,166667 \\
23. & TIF & $1000 \times 1000$ & 0,03125 & 0,03125 & 0,046875 & 1,5 \\
24. & TIF & $500 \times 500$ & 0,015625 & 0,015625 & 0,00955 & 0,6112 \\
25. & TIF & $250 \times 250$ & 0,00955 & 0,00955 & 0,00955 & 1 \\
\hline & & & & & &
\end{tabular}

Hasil analisis Tabel 3 yang didapat dari pengujian kecepatan enkripsi adalah semakin rendah pixel suatu ektensi semakin cepat pula kecepatan enkripsi, pixel suatu extensi juga mempengaruhi size file sebuah citra, di saat ukuran citra tersebut rendah atau sedikit kecepatan enkripsi juga semakin cepat, begitu juga sebaliknya.

\subsection{Analisis ruang kunci}

Serangan Brute-Force digunakan untuk mencoba kemungkinan key untuk dilakukan dekripsi. Ruang kunci dibuatcukup besar yang bertujuan agar serangan hacker dengan Brute Force kurang efektik atau tidak efektif, ruang kunci merupakan jumlah total key yang dapat diinputkan saat melakukan dekripsi[8].

Parameter kunci rahasia yang digunakan di dalam algoritma enkripsi ini memiliki satu buah key, yakni $p$. Dalam rancangan penelitihan ini satu key menggunakan 7 karakter, dimana 1 karakter mempunyai 8 bit dalam pegkodean ASCII. Sehingga 1 key memiliki 56 bit, maka nilai kemungkinan ruang kunci adalah sekitar $2^{56}=7.2 \times 10^{16}$.

$$
H=2^{p}
$$

Dengan menggunakan Persamaan 3, Ruang kunci seluruhnya adalah

$H=2^{56}$

$H=7.2 \times 10^{16}$

Ukuran Ruang Kunci ini cukup besar, sehingga algoritma dapat bertahan terhadap serangan Brute-Force Attack. 


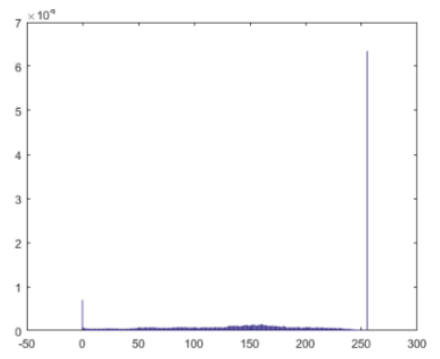

(a)

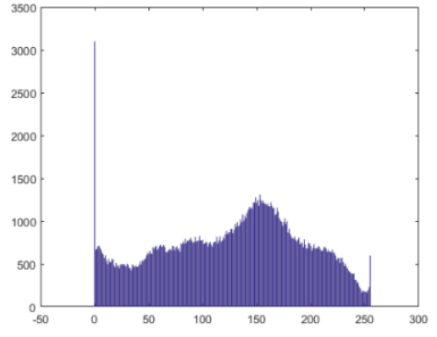

(b)

Gambar 4. (a) Histogram Citra Awal, (b) Histogram Enkripsi JPG

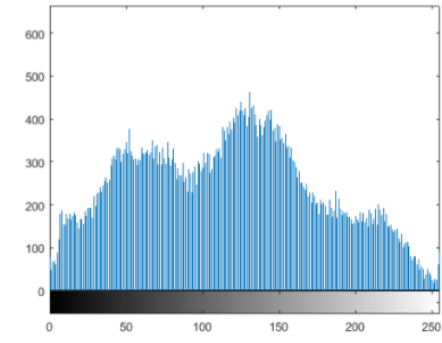

(a) Gray

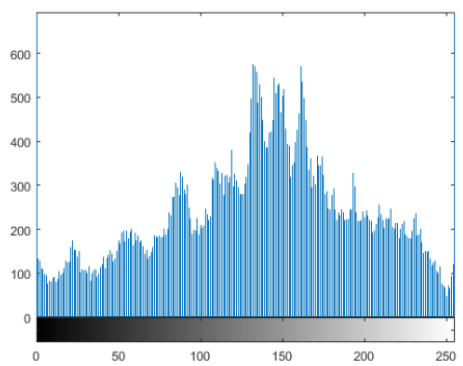

(b) Red

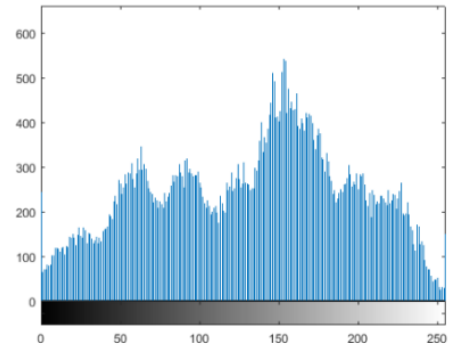

(c) Green

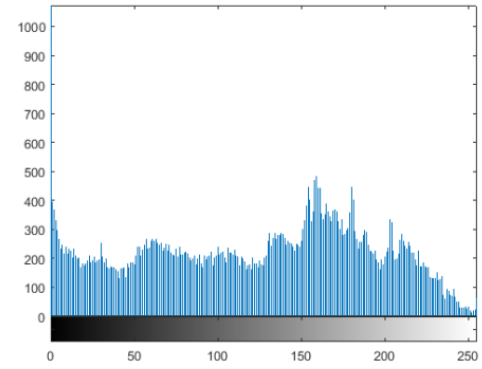

(d) Blue

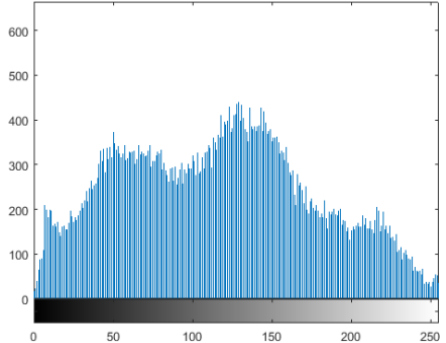

(e) Gray

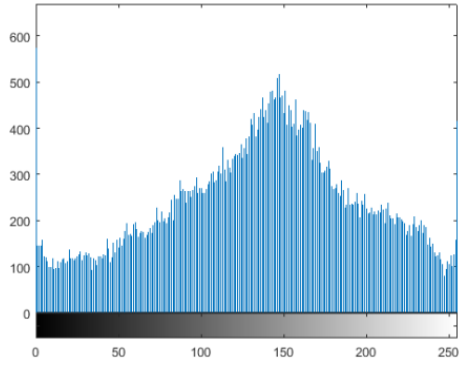

(f) Red

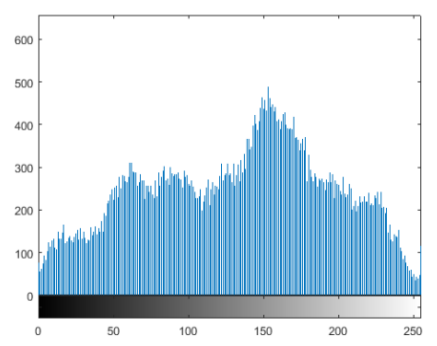

(g) Green

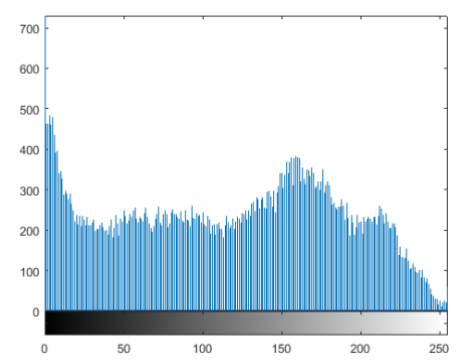

(h) Blue

Gambar 5. (A)-(D) Histogram Citra Awal Untuk Masing-Masing Kanal, Dan (E)-(H) Histogram ChiperImage Untuk Setiap Kanal 
Pengolahan citra histogram menunjukan penyeberan nilai pixel dalam sebuah citra. Pada saat peretas (hacker) memakai teknik histogram agar dapat melakukan kriptanalisis dengan memanfaatkan frekuensi kemunculan pixe/pada histogram. Dengan menganalisa frekuensi nilai pixel, peretas memperkirakan key atau pixel-pixel di dalam plain-image [9].

Agar tidak dapat memakai teknik histogram agar dapat memakai analisis frekuensi, sehingga histogram plain-image dan histogram cipher-image seharusnya berbeda secara signifikan atau secara statistik tidak memiliki kemiripan. Peretas (hacker) berharap nilai pixel yang sering muncul didalam plain-image berkorelasi dengan nilai pixel yang sering muncul di dalam cipher-image [10]. Oleh karena itu, harusnya histogram cipher-image datar (flat) atau berbeda dengan citra awal.

Gambar 4(a) menunjukkan histogram citra awal sebelum dienkripsi, dan Gambar 4(b) menunjukan histogram dari hasil enkripsi. Histogram dari Gambar 4(a) dan Gambar 4(b) terjadi perubahan setelah dienkripsi.

Gambar 5(a) sampai Gambar 5(d) memperlihatkan histogram citra awal sebelum dienkripsi (plain image) untuk setiap karnal warna Gray dan RGB, Gambar 5(e) sampai Gambar 5(h) adalah histogram masing-masing karnal warna pada cipher image. Sama seperti citra awal pada Gambar 4(a) dan Gambar 4(b) histogram chiper image pada setiap karnal Gray dan RGB juga terlihat berbeda dengan histogram plain image.

Kesimpulan dari analisis histogram adalah dengan menggunakan algoritma operasi rotasi dapat menunjukan histogram yang berbeda dengan citra awal, tetapi histogram yang baik harusnya berbeda secara signifikan atau secara statistik tidak memiliki kemiripan dan harusnya histogram chiper-image datar (flat) atau secara statistik memiliki distribusi (relatif) uniform, sehingga dapat disimpulkan algoritma operasi rotasi saja kurang efektif untuk enkripsi.

\section{Kesimpulan}

Berdasarkan hasil implementasi dan pengujian yang telah dilakukan dari tugas akhir yang berjudul "Rancang Bangun Aplikasi Enkripsi Citra berdasarkan Operasi Rotasi" dapat disimpulkan sebagai berikut:

1. Pesan yang berupa citra dapat dikonversi menjadi pesan enkripsi dan dekripsi, hasil proses enkripsi citra terjadi perubahan size file dan histogramnya, sedangkan hasil proses dekripsi mengalami perubahan size file namun memiliki histogram yang sama dengan citra awal.

2. Dari analisis perubahan size file proses enkripsi dan dekripsi, hanya file yang berektensi BMP yang memiliki size file yang tetap seperti file awal, sedangkan untuk ektensi JPG, BMP, PNG, dan TIF mengalami penurunan size file.

3. Dari analisis kecepatan proses enkripsi berpengaruh terhadap size file dan ektensi file pada citra. dari percobaan yang dilakukan, file berektensi BMP dan PNG pada ukuran pixel 2000X2000 memiliki pengkatan kecepatan terbaik yaitu sebesar $0.12 x$ lebih cepat.

\section{Daftar Notasi}

$H \quad=$ Hasil dari kombinasi karakter key

$p \quad=$ Jumlah bit pada key

\section{Referensi}

[1] Rizqi Firmansyah and W. Suadi, "Pada Media Gambar Dengan Menggunakan Metode Des Dan Region-Embed Data Density .," Byte, pp. 1-7, 2011.

[2] B. S. W. Poetro, P. Studi, T. Informatika, and U. Diponegoro, "Prosiding seminar nasional ilmu komputer universitas diponegoro 2010 semarang, 7 agustus 2010," pp. 175-178, 2010.

[3] D. Abrihama, "Keystream Vigenere Cipher: Modifikasi Vigenere Cipher dengan Pendekatan Keystream Generator," Progr. Stud. Inform. ITB. Bandung, 2008.

[4] Z. Liu, S. Li, M. Yang, W. Liu, and S. Liu, "Image encryption based on the random rotation operation in the fractional Fourier transform domains," Opt. Lasers Eng., vol. 50, no. 10, pp. 1352-1358, 2012.

[5] B. Santoso, "Bahasa Pemrograman Python di Platform GNU/LINUX," pp. 1-9, 2016.

[6] T. Heriyanto, "Pengenalan Kriptografi," p. 60, 1999.

[7] D. Putra, Pengolahan Citra Digital, 1st ed. Yogyakarta: ANDI OFFSET, 2010.

[8] R. Munir, "Digital Menggunakan Kombinasi Dua Chaos Map Dan Penerapan Teknik Selektif." 
[9] P. Ronsen, A. Halim, and I. Syahputra, "Enkripsi Citra Digital Menggunakan Arnold's Cat Map dan Nonlinear Chaotic Algorithm," JSM STMIK Mikroskil, vol. 15, no. 2, pp. 61-71, 2014.

[10] V. Yuniati, G. Indriyanta, and A. R. C, "Enkripsi dan Dekripsi dengan Algoritma AES 256 untuk Semua Jensis File," J. Inform., vol. 5, no. 1, pp. 22-31, 2009.

REPOSITOR, Vol. 1, No. 1, November 2019: 1-8 